\title{
Crossability Studies among Twenty Accessions of Roselle (Hibiscus sabdariffa L.)
}

\author{
J. Kwofie ${ }^{1}$, H. M. Amoatey ${ }^{1,2}$, W. Nunekpeku ${ }^{2}$, J. K. Ahiakpa ${ }^{3}$ \& C. Katsepor ${ }^{1}$ \\ ${ }^{1}$ Graduate School of Nuclear and Allied Sciences, Department of Nuclear Agriculture and Radiation Processing, \\ University of Ghana, Ghana \\ ${ }^{2}$ Biotechnology and Nuclear Agriculture Research Institute, Ghana Atomic Energy Commission, Ghana \\ ${ }^{3}$ Research Desk Consulting Ltd., Kwabenya-Accra, Ghana \\ Correspondence: J. Kwofie, Graduate School of Nuclear and Allied Sciences, Department of Nuclear Agriculture \\ and Radiation Processing, University of Ghana, Ghana. Tel: 233-(0)-249-689-816. E-mail: quoph2@gmail.com
}

Received: May 24, 2017

doi:10.5539/jas.v9n9p230
Accepted: August 2, $2017 \quad$ Online Published: August 15, 2017

URL: https://doi.org/10.5539/jas.v9n9p230

\begin{abstract}
Increasing exploitation of roselle (Hibiscus sabdariffa L.) and its products require that commercial varieties with superior attributes are developed to replace landrace varieties and to meet the growing demand for commercial-scale cultivation of the crop. In this study, twenty landrace varieties of roselle collected from three geographical regions of Ghana were artificially crossed in a pairwise mating scheme. The aim was to obtain relevant information pertaining to fertility status and extent of crossability among the accessions to facilitate breeding of improved varieties. Attempts at hybridisation were made both between and among 6 accessions of Hibiscus sabdariffa var Altissima and 14 accessions of Hibiscus sabdariffa var Sabdariffa. Crosses between accessions of Hibiscus sabdariffa var Altissima and Hibiscus sabdariffa var Sabdariffa yielded no hybrids, suggestive of a crossability barrier between the two mating groups. All intra-varietal crosses involving accessions of Hibiscus sabdariffa var Altissima were successful regardless of direction of cross while only few of the crosses among those of Hibiscus sabdariffa var Sabdariffa produced successful hybrids. Also fertility estimates of members of Hibiscus sabdariffa var Altissima were significantly higher $(30.00 \%-80.00 \%)$ compared to those of var Sabdariffa (0.00\%-43.00\%). This implies that complete pairwise design could be used for intra-varietal crosses involving accessions of Hibiscus sabdariffa var Altissima, whereas only a partial pairwise design is feasible for members of Hibiscus sabdariffa var Sabdariffa.
\end{abstract}

Keywords: crossability studies, Hibiscus sabdariffa L., crosses, accessions, roselle, vegetables

\section{Introduction}

Roselle (Hibiscus sabdariffa L.) is an important multipurpose crop grown in tropical and sub-tropical regions of the world for its stem fibre, edible calyces, leaves and seeds (Siti et al., 2017). It possesses huge potential as a crop of strategic importance for agricultural economies across West Africa due to its diverse uses as food (vegetables, source of oil, refreshing drink), medicine and a source of foreign exchange (fibre and natural colourants). It is rich in essential nutrients, particularly protein and iron whose deficiency is widespread especially among rural communities across the West African sub-region (Zaman et al., 2017; Chun-Tang et al., 2015).

Indeed, roselle ranks higher in nutrients and phytochemical contents than most cultivated crops in the tropics (Zaman et al., 2017; FAO, 2007). Additionally, a kind of non-alcoholic beverage obtained from the dry calyces known variously as "Bissap" or "Sobolobo" (Ghana) has gained popularity in recent years forming prominent part of refreshment packages served at various social gatherings throughout West Africa (Singh et al., 2017). Besides, genes for resistance to Yellow leaf mosaic virus infection whose damaging effect is ubiquitous among crops of the malvaceae family is reported to have been found in roselle germplasm (Chatterjee et al., 2005).

Very little effort has been directed to combine its outstanding nutritional qualities with other agronomically desirable traits in order to develop superior varieties for cultivation by farmers. Consequently, existing cultivars are wild extractions characterised by several undesirable traits such as conspicuous pubescence on almost every part of the crop, indeterminate flowering and fruiting habits as well as susceptibility to numerous diseases and 
pests. The presence of these traits has made roselle an unattractive crop for commercial cultivation by farmers. Although it is adapted to a wide range of agro-ecologies, it is currently cultivated on the least preferred parcels of land, often as a relay crop, thereby portraying it as a minor crop (Patel, 2014).

Concerted efforts are therefore required to reverse this trend beginning with hybridisation among existing cultivars to generate segregating populations, followed by recurrent selection of new varieties with combined superior attributes. However, a previous hybridisation study suggests possible crossability barrier among genotypes of roselle (Vaidya, 2000). A study of crossability is therefore crucial to provide relevant information on compatibility and fertility status of the various varieties of roselle cultivated in Ghana as potential sources of breeding materials for improvement of the crop. Knowledge of compatibility of available local cultivars would enable breeders to select appropriate mating design to accelerate improvement of the crop through breeding.

\section{Materials and Methods}

\subsection{Site of Experiment}

The study was undertaken at the research farm of the Biotechnology and Nuclear Agriculture Research Institute (BNARI) of the Ghana Atomic Energy Commission (GAEC) at Kwabenya, Accra. The site is located at $05^{\circ} 40^{\prime} \mathrm{N}$ and longitude $0^{\circ} 13^{\prime} \mathrm{W}$ with an elevation of $76 \mathrm{~m}$ above sea level within the coastal savannah agro-ecological zone of Ghana. The experiment was carried out from May, 2013 to November, 2013.

\subsection{Germplasm Assembly}

Twenty local accessions of roselle (H. sabdariffa); comprising 6 cultivars of Hibiscus sabdariffa var Altissima and 14 cultivars of Hibiscus sabdariffa var Sabdariffa collected from three geographic regions of Ghana (Northern, Volta and Western) were used as parents to produce F1 hybrids (Table 1).

Table 1. Identities and Geographic location of 20 Accessions used for the study

\begin{tabular}{llll}
\hline Number & Accession & Sub-species & Geographic Region \\
\hline 1 & A1 & Hibiscus sabdariffa var Sabdariffa & Northern \\
2 & A2 & “ & Northern \\
3 & A3 & “ & Volta \\
4 & A4 & “ & Volta \\
5 & A5 & “ & Volta \\
6 & A6 & “ & Volta \\
7 & A7 & “ & Northern \\
8 & A8 & “ & Volta \\
9 & A9 & “ & Western \\
10 & A10 & “ & Volta \\
11 & A11 & “ & Western \\
12 & A12 & “ & Western \\
13 & A13 & Hibiscus sabdariffa var Altissima & Western \\
14 & A14 & “ & Western \\
15 & D1 & “ & Northern \\
16 & D2 & “ & Northern \\
17 & D3 & D4 & Northern \\
18 & D6 & & Northern \\
19 & D5 & & Northern \\
20 & & & Northern \\
\hline
\end{tabular}

This sampling was done in order to obtain relevant information on compatibility and fertility status of the various varieties of roselle cultivated in Ghana for utilisation in further breeding work.

\subsection{Field Planting}

Seeds of each accession were sown manually on the field in a row of ten stands separated at a distance of $60 \mathrm{~cm}$ between rows and $30 \mathrm{~cm}$ within rows. Five seeds of each accession were initially sown and later thinned to two plants per stand at two weeks after emergence. Prior to sowing of seeds, the vegetation cover of the field was 
cleared and ploughing was undertaken to loosen the soil. Seeds of each accession were also planted in pots filled with potting medium comprising three parts of soil to one part of manure. The plants sown in pots were also thinned to two plants per pot at two weeks after emergence. Watering was done twice daily throughout the period. No fertiliser was applied.

\subsection{Emasculation and Pollination}

At flowering, ten healthy plants of each accession comprising five plants from the field and five from the pots were selected to serve as parents for hybridisation. Emasculation was carried out prior to pollination, by carefully removing anthers from matured buds which were due to open the next day using a fine-tip forceps to prevent self-pollination. Between successive emasculation of flowers belonging to different accessions, the pair of forceps was sterilised with alcohol to prevent contamination with pollen from earlier sources

Pollination was performed by dusting the stigma of the emasculated flower with pollen from a selected male parent. For each cross, thirty flowers were pollinated and reciprocal crosses were also made from 6:00 am to 10:00 am over a period of 8 weeks. Immediately after emasculation and pollination, the flower buds were covered with paper bags and clipped to prevent contamination from undesirable pollen and tagged with a label in order to identify the pollen donor and recipient as well as the time at which each particular cross was made.

\subsection{Evaluation of Hybridisation Success}

Compatibility was assessed through observation of each flower up to two weeks after pollination. Fertilised flowers developed fruit capsules with seeds between 7 to 14 days after pollination depending on the accessions involved in the cross. Where fertilisation failed the flowers dropped 2 to 3 days after pollination.

Hybridisation success of each cross was calculated according to the formula of Nunekpeku et al. (2012):

$$
\text { Hybridisation success }(\%)=\frac{\text { Number of fruits formed }}{\text { Number of flowers pollinated }} \times 100 \%
$$

Data obtained from the plants planted in the field and those maintained in pots were combined to calculate the values for the hybridisation success.

\section{Results}

3.1 Cross Compatibility Estimates among Accessions of Hibiscus sabdariffa var Altissima and Hibiscus sabdariffa var Sabdariffa

No hybrids were recorded from inter-varietal crosses between accessions of var Altissima and var Sabdariffa in this study (Table 2). All attempts at hybridisation across the two crossing groups failed to develop fruit capsules as flowers shriveled and abscised two or three days after pollination.

Table 2. Estimates of inter-varietal crossability between accessions of Hibiscus sabdariffa var Altissima and Hibiscus sabdariffa var Sabdariffa

\begin{tabular}{llllll}
\hline Cross & \multicolumn{3}{c}{ Number of crosses } & \multirow{2}{*}{ Compatibility } & Comment \\
\cline { 2 - 4 } Female/Male & Attempted & Successful & Unsuccessful & & No fruits formed \\
\hline A1 $\times$ D2 & 30 & 0 & 30 & No & No \\
D2 $\times$ A1 & 30 & 0 & 30 & No fruits formed \\
A3 $\times$ D6 & 30 & 0 & 30 & No & No fruits formed \\
D6 $\times$ A3 & 30 & 0 & 30 & No fruits formed \\
A9 $\times$ D1 & 30 & 0 & 30 & No & No fruits formed \\
D1 $\times$ A9 & 30 & 0 & 30 & No & No fruits formed \\
A2 $\times$ D5 & 30 & 0 & 30 & No fruits formed \\
D5 $\times$ A2 & 30 & 0 & 30 & No & No fruits formed \\
A11 $\times$ D3 & 30 & 0 & 30 & No fruits formed \\
D3 $\times$ A11 & 30 & 0 & 30 & & No fruits formed \\
\hline
\end{tabular}

However, hybrids were obtained from intra-varietal crosses among accessions of both Hibiscus sabdariffa var Altissima and Hibiscus sabdariffa var Sabdariffa although to varying degrees in different cross combinations. All direct and reciprocal crosses among accessions of Hibiscus sabdariffa var Altissima were successful (Table 3). Also, average crossability estimates among accessions in this group were very close ranging from $46.67 \%$ to 55.33 (where each accessions was repeatedly crossed as female parent to the other accessions) and $42.67 \%$ to 
$55.33 \%$ in reciprocal direction. The cross between accession D3 (female) and D4 (male) scored the highest success rate $(80 \%)$ among the individual cross combinations in this group while D1 $\times$ D5, D3 $\times$ D1, and D6 $\times$ D1 recorded the least value $(30 \%)$.

Table 3. Intra-varietal crossability estimates among six accessions of Hibiscus sabdariffa var Altissima

\begin{tabular}{|c|c|c|c|c|c|c|c|}
\hline \multirow{2}{*}{$\begin{array}{l}\text { Female parent }(+) \\
\text { Accession }\end{array}$} & \multicolumn{6}{|c|}{ Male parent $(\overbrace{}^{\Uparrow})$} & \multirow{2}{*}{ Mean } \\
\hline & D1 & D2 & D3 & D4 & D5 & D6 & \\
\hline D1 & & 63.30 & 50.00 & 40.00 & 30.00 & 56.67 & 48.00 \\
\hline D2 & 73.33 & & 46.67 & 36.67 & 63.33 & 56.67 & 55.33 \\
\hline D3 & $\underline{30.00}$ & 46.67 & & 80.00 & 41.94 & 40.00 & 48.00 \\
\hline D4 & 36.67 & 50.00 & 60.00 & & 33.33 & 53.33 & $\underline{46.67}$ \\
\hline D5 & 43.33 & 40.00 & 53.33 & 50.00 & & 50.00 & 47.33 \\
\hline D6 & $\underline{30.00}$ & 76.67 & 50.00 & 50.00 & 43.33 & & 50.00 \\
\hline Mean & 42.67 & 55.33 & $\mathbf{5 4 . 6 7}$ & 53.33 & 42.67 & 51.33 & \\
\hline
\end{tabular}

Note. Bolded and underlined values represent highest and least values, respectively.

Most cross combinations attempted among accessions of Hibiscus sabdariffa var Sabdariffa failed as only 31 successful hybrids $(20 \%)$ out of a possible 155 were obtained (Table 4). Additionally, only two cross combinations in this group (A1 $\times$ A11 and A10 $\times$ A11) were successful in both direct and reciprocal directions. Accessions A11 and A3 emerged the most prolific female and male parents, yielding 11 and 6 successful hybrids respectively. On the other hand, A2, A13, and A14 failed to produce any hybrids in all crosses in which they were deployed as female parents.

Also, crossability estimates recorded for members of this crossing group were relatively low and varied significantly ( 0.00 to $43.33 \%)$. Accessions A11 and A3 recorded the highest average crossability estimates $(23.00 \%$ and $13.00 \%)$ as female and male parents respectively.

Table 4. Intra-varietal crossability estimates among 14 accessions of Hibiscus sabdariffa var Sabdariffa

\begin{tabular}{lcccccccccccccccc}
\hline Male parent $\left(\begin{array}{l}\text { ( }) \\
\text { Accession }\end{array}\right.$ & Female parent $(+)$ ( $)$ & $\mathbf{A 1}$ & $\mathbf{A 2}$ & $\mathbf{A 3}$ & $\mathbf{A 4}$ & $\mathbf{A 5}$ & $\mathbf{A 6}$ & $\mathbf{A 7}$ & $\mathbf{A 8}$ & $\mathbf{A 9}$ & $\mathbf{A 1 0}$ & $\mathbf{A 1 1}$ & $\mathbf{A 1 2}$ & $\mathbf{A 1 3}$ & $\mathbf{A 1 4}$ & Mean \\
\hline $\mathbf{A 1}$ & & 0.00 & 0.00 & 0.00 & 0.00 & $*$ & 0.00 & 0.00 & 0.00 & 0.00 & 3.33 & 0.00 & $*$ & $*$ & 0.00 \\
A2 & $*$ & & $*$ & 0.00 & 0.00 & 0.00 & $*$ & 0.00 & 0.00 & 0.00 & 0.00 & 0.00 & 0.00 & 0.00 & 0.00 \\
A3 & 0.00 & 0.00 & & $*$ & 0.00 & $*$ & 32.33 & 0.00 & $*$ & 0.00 & 0.00 & 0.00 & 0.00 & 16.67 & 2.08 \\
A4 & 16.67 & 3.33 & 10.00 & & 0.00 & 0.00 & 0.00 & 0.00 & 0.00 & $*$ & 16.67 & 19.35 & 0.00 & $*$ & 5.50 \\
A5 & 0.00 & $*$ & 23.33 & $*$ & & 0.00 & $*$ & 0.00 & 0.00 & 0.00 & 0.00 & 0.00 & 0.00 & 0.00 & 2.30 \\
A6 & 0.00 & 0.00 & 0.00 & 0.00 & $*$ & & 0.00 & 0.00 & 0.00 & $*$ & 23.33 & 0.00 & $*$ & 0.00 & 2.30 \\
A7 & 0.00 & 0.00 & 0.00 & 0.00 & 0.00 & 0.00 & & $*$ & 0.00 & 0.00 & 0.00 & 16.67 & 0.00 & $*$ & 1.50 \\
A8 & 0.00 & 0.00 & $*$ & 0.00 & 23.33 & 0.00 & 0.00 & & 0.00 & 0.00 & $*$ & 0.00 & 0.00 & 0.00 & 2.60 \\
A9 & 36.67 & 0.00 & 30.00 & 0.00 & 40.00 & 0.00 & 30.00 & $*$ & & 0.00 & $*$ & 0.00 & 0.00 & 0.00 & 12.42 \\
A10 & 0.00 & 0.00 & 20.00 & 0.00 & 0.00 & 0.00 & 13.33 & $*$ & $*$ & & 26.67 & 0.00 & $*$ & 0.00 & 6.00 \\
A11 & 16.67 & 13.33 & 16.67 & $*$ & 23.33 & 36.67 & 26.67 & 20.00 & 30.00 & 16.67 & & $*$ & 36.67 & 16.67 & $\mathbf{2 3 . 0 0}$ \\
A12 & 0.00 & 0.00 & $\mathbf{4 3 . 3 3}$ & 0.00 & 0.00 & $*$ & 0.00 & 0.00 & $*$ & $*$ & 0.00 & & 0.00 & 0.00 & 4.30 \\
A13 & 0.00 & $*$ & 0.00 & 0.00 & $*$ & 0.00 & 0.00 & 0.00 & 0.00 & 0.00 & 0.00 & $*$ & & 0.00 & 0.00 \\
A14 & $*$ & 0.00 & 0.00 & 0.00 & 0.00 & 0.00 & $*$ & 0.00 & 0.00 & 0.00 & 0.00 & 0.00 & $*$ & \\
- Mean & 5.38 & 1.5 & $\mathbf{1 3 . 0 3}$ & 0.00 & 7.22 & 5.58 & 5.38 & 2.22 & 2.31 & 2.08 & 5.13 & 3.00 & 5.24 & 2.08 \\
\hline
\end{tabular}

Note. Bolded values represent highest values. $*=$ Cross not carried out due to poor flowering by some parents.

\subsection{Crossability Success with Respect to Time of the Day}

Table 5 shows pooled data for crossability success involving 20 accessions of roselle (Hibiscus sabdariffa) in relation to the time of day during which crosses were made. Success rate was significantly higher during the early hours of the day but decreased steadily in subsequent hours. Crosses made at 6 am-7 am were most 
successful (15.18\%), followed by 7 am-8 am (10.00\%), 8 am-9 am (8.94\%) and 9 am-10 am (7.62\%) in decreasing order.

Table 5. Variation in crossability success with respect to time of day

\begin{tabular}{lllll}
\hline \multirow{2}{*}{ Time } & \multicolumn{3}{c}{ Number of Crosses } & \multirow{2}{*}{ Crossability Success (\%) } \\
\cline { 2 - 4 } & Attempted & Successful & Unsuccessful & \\
\hline 6 am-7 am & 939 & 143 & 796 & $\mathbf{1 5 . 1 8}$ \\
$7 \mathrm{am}-8 \mathrm{am}$ & 779 & 78 & 701 & 10.00 \\
$8 \mathrm{am}-9 \mathrm{am}$ & 498 & 45 & 453 & 8.94 \\
$9 \mathrm{am}-10 \mathrm{am}$ & 729 & 56 & 673 & 7.62 \\
\hdashline Mean & $\mathbf{7 3 6 . 2 5}$ & $\mathbf{8 0 . 5 0}$ & $\mathbf{6 5 5 . 7 5}$ & $\mathbf{1 0 . 4 4}$ \\
\hline
\end{tabular}

\section{Discussion}

\subsection{Inter and Intra-Varietal Compatibility and Fertility Rates among Accessions of Hibiscus sabdariffa var Altissima and var Sabdariffa}

Detailed studies on extent of crossability among potential breeding material projected as critical for achieving useful gene combinations have largely been overlooked in roselle by scientists (Baack et al., 2015). This presents an obvious challenge in the quest to speedily develop improved varieties of the crop to meet its growing demand by end-users. In this regard, the accessions used this study were selected to provide an opportunity to investigate possibility of hybridisation across and among the major mating groups of the species (i.e. Hibiscus sabdariffa var Altissima and Hibiscus sabdariffa var Sabdariffa).

The outcome of the study suggest an apparent crossability barrier between Hibiscus sabdariffa var Altissima and Hibiscus sabdariffa var Sabdariffa, implying that successful hybridisation across the two mating groups may not be achievable through conventional crossing approach. However, accessions of Hibiscus sabdariffa var Altissima are readily crossable with one another and also exhibit relatively high fertility which makes complete pair-wise crossing such as full diallele design (Griffing, 1956) among them easily attainable as previously reported (Louis et al., 2013).

The analyses also show that fertility rates of accessions of Hibiscus sabdariffa var Sabdariffa are very low, exhibiting partial incompatibility among members of this crossing group. These findings are in consonance with observations of Vaidya (2000), who also found low crossability rates during a natural hybridisation studies in Hibiscus sabdariffa var Sabdariffa. These outcomes denote that only partial pair-wise design (Todd, 2013) may be possible for intra-varietal crosses involving accessions of Hibiscus sabdariffa var Sabdariffa.

Results obtained in this study also indicate that the possibility of hybridisation largely reflects geographical proximity between accessions. This view is strengthened by the relatively high hybridisation estimates among accessions of Hibiscus sabdariffa var Altissima which mostly belong to the same geographical region compared to the relatively low successes recorded for Hibiscus sabdariffa var Sabdariffa which comprise accessions with widely differing geographical locations. Various authors have attributed such outcomes to reproductive barriers between the different ecotypes of a species (Todd, 2013; Valdiani et al., 2012).

\subsection{Variation in Crossability Success with Respect to Time of Day}

Percent crossability varied inversely with the course of time. This agrees with a report by (Samba, 2013) working on sweet potato (Ipomoea batatas L.) under the similar local conditions. It however, contradicts the report by $(\mathrm{Li}, 2000)$ working on kenaf (H. cannabinus) in China. This variation may be attributable to the different environmental conditions as the two species are closely related. Indeed, environmental conditions affect successful pollination of crops. In this study, favourable environmental conditions such as low temperature and high humidity which are usually recorded during the early hours of the day may have accounted for the comparatively higher crossability success during this period (Koike et al., 2015).

Moreover, pollen viability and stigma receptivity are known to peak in the period immediately after opening of flowers (6 am-7 am) resultant of cleistogamous mode of pollination of roselle (Vaidya, 2000). Thus, crosses made in early hours of the day are more likely to be successful than those conducted later then. Besides, increasing stigma desiccation and abscission with the course of the day may have accounting for the low success of crossability in the later part of the day (Bishop et al., 2016; Munguía-Rosas et al., 2012). 


\section{Conclusion}

The study indicates that successful cross-fertilisation between Hibiscus sabdariffa var Altissima and var Sabdariffa may require special techniques beyond conventional cross pollination in the field. It was, however, observed that accessions of Hibiscus sabdariffa var Altissima may be crossed in a complete pair-wise design, whereas those of Hibiscus sabdariffa var Sabdariffa may, at best, be crossed through partial pair-wise designs. Even so, successful hybridisation among accessions of the later may be difficult to achieve. Thus, greater number of crosses should be attempted to increase the probability of successful hybridization, preferably in early hours of the day. These findings would serve as a guide to future breeding of roselle in Ghana.

\section{Acknowledgements}

The authors wish to thank Management of Biotechnology and Nuclear Agriculture Research Institute (BNARI) of Ghana Atomic Energy Commission (GAEC) for allowing their facilities to be used for the research. We are also very grateful to all research scientists of the institute for their cooperation and support during this investigation.

\section{References}

Baack, E., Melo, M. C., Rieseberg, L. H., \& Ortiz-Barrientos, D. (2015). The origins of reproductive isolation in plants-A review. New Phytologist, 3-6. https://doi.org/10.1111/nph.13424

Bishop, J., Potts, S. G., \& Jones, H. E. (2016). Susceptibility of faba bean (Vicia faba L.) to heat stress during floral development and anthesis. Journal of Agronomy and Crop Science, 202, 508-517. https://doi.org/ $10.1111 /$ jac. 12172

Chatterjee, A., Roy, A., Padmalatha, K. V., Malathi, V. G., \& Ghosh, S. K. (2005). Occurrence of a Begomovirus with yellow vein mosaic disease of Mesta (Hibiscus cannabinus and Hibiscus sabdariffa). Australasian Plant Pathology, 34(10), 609-610. https://doi.org/10.1071/AP05062

Chun-Tang, C., Jing-Hsien, C., Fen-Pi, C., \& Hui-Hsuan, L. (2015). Hibiscus sabdariffa Leaf Extract Inhibits Human Prostate Cancer Cell Invasion via Down-Regulation of Akt/NF-kB/MMP-9 Pathway. Nutrients, 7, 5065-5087. https://doi.org/10.3390/nu7075065

Da-Costa-Rocha, I., Bonnlaender, B., Sievers, H., Pischel, I., \& Heinrich, M. (2014). Hibiscus sabdariffa L.-A phytochemical and pharmacological review. Food Chemistry, 165, 424-443. https://doi.org/10.1016/ j.foodchem.2014.05.002

FAO. (2007). Protein and amino requirements in human nutrition (pp. 932-935). Report of a joint WHO/FAO/UNU expert consultation. Geneva, Switzerland, WHO Technical Report Series.

Griffing, B. (1956). Concept of general and specific combining ability in relation to diallele crossing system. Australian Journal of Biological Sciences, 6(4), 463-493. https://doi.org/10.1071/BI9560463

Koike, S., Yamaguchi, T., Ohmori, S., Hayashi, T., Yatou, O., \& Yoshida, H. (2015). Cleistogamy decreases the effect of high temperature stress at flowering in rice. Plant Production Science, 18, 111-117. https://doi.org/ 10.1626/pps.18.111

Louis, S. J., Kadams, A. M., Simon, S. Y., \& Mohammed, S. G. (2013). Combining Ability in roselle cultivars for agronomic traits in Yola, Nigeria. Greener Journal of Agricultural Sciences, 3(2), 145-149.

Munguía-Rosas, M. A., Parra-Tabla, V., Ollerton, J., \& Cervera, J. C. (2012). Environmental control of reproductive phenology and the effect of pollen supplementation on resource allocation in the cleistogamous weed, Ruellia nudiflora (Acanthaceae). Annals of Botany, 109, 343-350. https://doi.org/ $10.1093 / \mathrm{aob} / \mathrm{mcr} 284$

Nunekpeku, W., Amoatey, H. M., Oduro, V., \& Klu, G. Y. P. (2012). Crossability Studies in 392 Cassava in the Coastal Savanna Zone of Ghana. Asian Journal of Agricultural Sciences, 4(4), 393 236-241.

Patel, S. (2014). Hibiscus sabdariffa: An ideal yet under-exploited candidate for nutraceutical applications. Biomedicine and Preventive Nutrition, 4(1), 23-27. https://doi.org/10.1016/j.bionut.2013.10.004

Samba, J. A. (2013). Flowering Induction and Cross Compatibility Studies for Sweet Potato (Ipomoea batatas L.) Breeding (pp. 28-35, MSc. Thesis, Department of Crop and Soil Sciences, Faculty of Agriculture, Kwame Nkrumah University of Science and Technology, Kumasi, Ghana). 
Singh, P., Khan, M., \& Hailemariam, H. (2017). Nutritional and Health Importance of Hibiscus Sabdariffa: A Review and Indication for Research Needs. Journal of Nutritional Health and Food Engineering, 6(5), 1-4. https://doi.org/10.15406/jnhfe.2017.06.00212

Siti, A. R., Noer, H. D., Asmah, A., Mohamad, O., Maheran, A., \& Mohd, R. M. N. (2017). Protoplast Isolation from Hibiscus sabdariffa L. Advanced Science Letters, 23, 1333-1336. https://doi.org/10.1166/asl.2017. 8362

Todd, S. M. (2013). Application of Near Infrared Spectroscopy to Study Inheritance of Sweet Potato Composition Traits (pp. 29-54, PhD Dissertation, North Carolina State University, Department of Horticultural Science, Raleigh, North Carolina).

Vaidya, K. R. (2000). Natural cross-pollination in roselle (Hibiscus sabdariffa L.). (Malvaceae). Genetics and Molecular Biology, 23(3), 667-669. https://doi.org/10.1590/S1415-47572000000300027

Valdiani, A., Mihdzar, A. K., Mohd, S. S., Daryush, T., Vahid, O., \& Chia, S. H. (2012). Intraspecific Crossability in Andrographis paniculata Nees: A Barrier against Breeding of the 407 Species. Scientific World Journal, 6(11), 1-9. https://doi.org/10.1100/2012/297545

Zaman, H. U., Das, P., Das, P., \& Sahu, N. K. (2017). Analysis of Physicochemical, Nutritional and Antioxidant Properties of Fresh and Dried Roselle (Hibiscus sabdariffa Linn.) Calyces. International Journal of Pure and Applied Bioscience, 5(1), 261-267. https://doi.org/10.18782/2320-7051.2532

\section{Copyrights}

Copyright for this article is retained by the author(s), with first publication rights granted to the journal.

This is an open-access article distributed under the terms and conditions of the Creative Commons Attribution license (http://creativecommons.org/licenses/by/4.0/). 